2

3

4

5

\title{
Antimicrobial activities and phytochemical analysis of Tamarix gallica extracts
}

Mondher Boulaaba ${ }^{1,2^{*}}$, Mejdi Snoussi ${ }^{3}$, Mariem Saada ${ }^{1}$, Khaoula Mkadmini ${ }^{1}$, Abderrazak Smaoui $^{2}$, Chedly Abdelly ${ }^{2}$ and Riadh Ksouri ${ }^{1}$

${ }^{1}$ Laboratoire des Ecoprocédés et de Valorisation des Plantes Aromatiques et Médicinales, Centre de Biotechnologie de Borj-Cédria, Technopole de Borj-Cédria, BP 901, 2050 Hammam-Lif, Tunisie

${ }^{2}$ Laboratoire des Plantes Extrêmophiles, Centre de Biotechnologie de Borj-Cédria, Technopole de Borj-Cédria, BP 901, 2050 Hammam-Lif, Tunisie

${ }^{3}$ Laboratoire de Traitement et de Recyclage des Eaux, Centre de Recherches et des Technologies des Eaux (CRTE), Technopole de Borj-Cédria, BP 273, 2050 Hammam-Lif, Tunisie

\section{Footnotes}

*Corresponding author: Mondher Boulaaba

Tel: +21679325848, Fax: +21679325638, E-mail address: mondher1382@ gmail.com 列

(

(

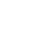

3




\section{Abstract}

Microbial contaminations and resistance to antibiotics suggest us to explore the traditional medicine mainly by discovering new natural products from plants like Tamarix genus. In the present work, the antimicrobial activities of Tamarix gallica leaves and flowers were assessed. Results showed that flower extracts have the highest antibacterial activity especially against Micrococcus luteus ( $\mathrm{zi}=25 \mathrm{~mm}$ ). This organ is also distinguished by the best antifungal activities especially against Candida glabrata (zi=14.67 mm) and Candida albicans $(\mathrm{zi}=14.33 \mathrm{~mm})$. The minimum inhibitory concentration (MIC) values were identical for all samples except for Candida albicans (MIC=0,292 mg/mL). Regarding the minimal bactericidal concentrations (MBCs), results showed concentrations superior to $37 \mathrm{mg} / \mathrm{mL}$ using leaf extracts and $18 \mathrm{mg} / \mathrm{mL}$ using flower ones. Thereby, flower and leaf extracts showed a bacteriostatic effect. The phytochemical tests by LC-ESI-TOF-MS demonstrated the presence of five flavonoids in flower extracts including quercetin and kaempferol. However, the extract from leaves showed the existence of six compounds including quercetin 3-Oglucuronide. These data suggest that Tamarix gallica could be a promising source of natural products in the field of functional foods and nutraceutical industries.

Keywords: Tamarix gallica; Phenolics; Antimicrobial activity; LC-ESI-TOF-MS. (1) 0 1 62 63 4 5 6 67 8 


\section{Introduction}

The resistance of some strains to antibiotics improves the research on natural antimicrobial agents from microorganisms (De Lima Procópio et al., 2012) and plants (Mulaudzi et al., 2011). In fact, different natural molecules induce growth inhibition of bacteria and fungi as well as death (Boulekbache-Makhlouf et al., 2013; Khan et al., 2009). In this context, a particular interest is accorded to halophytes as a source of phenolic compounds. These secondary metabolites, which are derived from phenylpropanoid and shikimate pathways, are synthesized in different plant parts and make contribution to eliminating the accumulation of reactive oxygen species (ROS) at toxic level during abiotic stresses (Naczk and Shahidi, 2006). Phenolic extracts present large biological properties such as antiinflammatory (Oueslati et al., 2012), anticancer (Boulaaba et al., 2013a, 2013b; Oueslati et al., 2012), and cardiovascular protection (Stoclet et al., 2004) effects. Moreover, phenolics possess a considerable antimicrobial capacity against a large number of pathogenic strains (Eldeen et al., 2011; Rodríguez Vaquero et al., 2010). This capacity can procure to plants a protection against microorganisms (Cushnie and Lamb, 2005). The inhibition of growth could be due to the permeability and the destruction of the microbial membrane, inhibiting synthesis of nucleic acids and bacteria inhibiting energy metabolism (Cushnie and Lamb, 2011). Moreover, the high sensitivity of some fungi may be due to an effect on the cell signalling. For example, the 3,4-methylenedioxyphenol, a phenolic compound obtained from sesame seed oil of Sesamum sp., has an anti-candidal activity against $C$. albicans by the disruption of calcineurin signalling pathway (Ansari et al., 2014). During stress conditions, this serinethreonine phosphatase is essential to the survival and for the virulence of $C$. albicans (Blankenship et al., 2003). On the other hand, previous studies have shown that the biosynthesis of phenolics in plants, in terms of quantity and quality, depends on physiological factors (genotype, organ and period of collect), and on environmental conditions (temperature, salinity, drought, light intensity and bacterial infection) (Lisiewska et al., 2006; Moore et al., 2006). This production may reflect the physiological status and developmental stages of plant (Lisiewska et al., 2006).

In Tunisia, several plants are used in traditional medicine. In this context, research indicates that $T$. gallica may have chemopreventive potential against liver diseases (Sehrawat and Sultana, 2006). Moreover, this plant has an antiproliferative effect on colon cancer Caco2 cells (Boulaaba et al., 2013b). Indeed, Tamarix spp. was employed in traditional medicine as astringent, aperitif, stimulant of perspiration, diuretic (Saidana et al., 2008), and active against leucoderma, spleen trouble and eye diseases (Sharma and Parmar, 1998). In addition, 
previous works reported the relation between antimicrobial activities and bioactive molecules likes phenolics provided from extracts of $T$. gallica (Ksouri et al., 2009), T. ramosissima (Sultanova et al., 2001) and T. hispida (Sultanova et al., 2004). The superiority of flower antimicrobial activities of $T$. gallica can be explained by its phytochemical analysis. In fact, natural phenolics as catechin, quercetin and gallic acid were known for their high antibacterial activity against E. coli, P. aeruginosa and S. aureus (Rodriguez Vaquero et al., 2007). The same effect was shown with coumarin, as a secondary metabolite, against Gram-positive bacteria likes Staphylococcus aureus and Bacillus cereus (De Souza et al., 2005). Moreover, recent study showed significant antibacterial activities of essential oils from the aerial parts of T. boveana (Saidana et al., 2008).

In the present work, we set out to investigate (i) the antimicrobial activity of phenolic extracts against several pathogenic microorganisms with the determination of the minimal inhibition concentration (MIC) and the minimal bactericidal concentration (MBC) values and (ii) the possibly phenolics involved in this antimicrobial effect.

\section{Materials and methods}

\subsection{Plant material}

Tamarix gallica (Tamaricaceae) leaves and flowers were harvested at full flowering stage from the sebkha of El Kelbia locality (20 km north-east Kairouan; superior semi-arid bioclimatic stage; mean annual rainfall: $400 \mathrm{~mm}$ ). The harvested organs were rinsed with distilled water, then oven-dried for $48 \mathrm{~h}$ at $60^{\circ} \mathrm{C}$, and ground to a fine powder. This halophyte was identified at the Biotechnology Center of Borj-Cédria, and a voucher specimen was deposited at the Herbarium of the laboratory (Laboratoire des Ecoprocédés et de Valorisation des Plantes Aromatiques et Médicinales).

\subsection{Extraction of phenolic compounds}

Extract powder of flowers and leaves were obtained by maceration of $2.5 \mathrm{~g}$ dry powder in $25 \mathrm{~mL}$ of $80 \%$ methanol for 24 hours. Extracts were filtered through a Whatman $\mathrm{n}^{\circ} 4$ filter paper and evaporated under reduced pressure at $35^{\circ} \mathrm{C}$ using rotary vacuum evaporator. At last, flower and leaf extracts were dissolved in DMSO to get $300 \mathrm{mg} / \mathrm{mL}$. DMSO was used to avoid any toxicity. For the antimicrobial effect analysis, three 
concentrations $(50,100$ and $300 \mathrm{mg} / \mathrm{mL})$ of plant extracts were tested against 16 microbial strains (12 bacteria and 4 fungi) and allowed to stand for 24 hours in obscurity at $37^{\circ} \mathrm{C}$.

\subsection{Assessment of antimicrobial activities}

\subsubsection{Determination of antibacterial activity}

The antibacterial activity of leaf and flower extracts was screened by the agar disk diffusion assay (Hajlaoui et al., 2008) against 12 human pathogenic ATCC strains including Gram-negative bacteria: Pseudomonas aeruginosa (ATCC 27853), Salmonella arizonae (DMB 560), Escherichia coli (ATCC 35218), Klebsiella sp. (CIP Tunis), and Gram-positive ones: Staphylococcus aureus (ATCC 29213), Micrococcus luteus (NCIMB 8166), Enterococcus faecalis (ATCC 29212), Bacillus subtilis (ATCC 6623), Listeria monocytogenes (ATCC 19115), Staphylococcus aureus Methicillin Resistant, Bacillus thuringiensis (DH 110), and Bacillus cereus (ATCC 14579). Bacterial strains were first grown on Muller Hinton medium at $37{ }^{\circ} \mathrm{C}$ for $24 \mathrm{~h}$ prior to seeding onto the nutrient agar. Four Candida species (C. parapsilosis, ATCC 22019; C. albicans, ATCC 90026; C. krusei ATCC 6258; and C. glabrata ATCC 90030) were first grown on Sabouraud chloramphenicol agar plate at $30^{\circ} \mathrm{C}$ for 18 to $24 \mathrm{~h}$. All microorganisms were kindly provided by Dr. Mejdi Snoussi from the Laboratoire de Traitement et de Recyclage des Eaux, Centre de Recherches et des Technologies des Eaux (CRTE), Technopole de Borj-Cédria. Each inoculum of the respective yeast was streaked onto Sabouraud chloramphenicol agar plates at $30^{\circ} \mathrm{C}$ using a sterile swab. In this study, we preferred using Muller Hinton medium because it is not specific to one strain. However, all Candida were grown on Sabouraud medium supplemented with chloramphenicol because it is more appropriate to select the wished yeasts. During the antibacterial and antifungal tests, a sterile filter disk (diameter $6 \mathrm{~mm}$, Whatman paper $\mathrm{n}^{\mathrm{o}} 3$ ) was placed on the medium seeded with strains, and $10 \mu \mathrm{L}$ of each DMSO extract $(50,100$ and $300 \mathrm{mg} / \mathrm{mL}$ ) were dropped onto each paper disk (Hajlaoui et al., 2008). The plates were incubated at $37^{\circ} \mathrm{C}$ for 18 to $24 \mathrm{~h}$. The diameter of the zones of inhibition around each of the discs was taken as measure of the antimicrobial activity. Disks with $10 \mu \mathrm{L}$ of DMSO were used as negative controls. Gentamicine and Chloramphenicol were used as positive controls against bacteria and Amphotericine B one $(20 \mu \mathrm{g})$ against fungi. Each experiment was carried out in triplicate.

\subsubsection{MIC and MBC assays}


Minimal inhibition concentrations (MICs) and the minimal bactericidal concentrations (MBCs) values were determined for all bacterial strains used in this study as described by Gulluce et al. (2007). Each extract, dissolved in 10\% dimethylsulfoxide (DMSO), was first diluted to the highest concentration, and then serial two-fold dilutions were made in a concentration range from 0,146 to $150 \mathrm{mg} / \mathrm{mL}$ for all extracts in $5 \mathrm{~mL}$ sterile test tubes containing nutrient broth. The 96-well plates were prepared by dispensing into each well 95 $\mu \mathrm{L}$ of nutrient broth and $5 \mu \mathrm{L}$ of the inoculum. From the stock solutions of each extract, 100 $\mu \mathrm{L}$ aliquot were added into the first wells. Then, $100 \mu \mathrm{L}$ from the serial dilutions were transferred into eleven consecutive wells. The last well containing $195 \mu \mathrm{L}$ of nutrient broth without extract and $5 \mu \mathrm{L}$ of the inoculum on each strip was used as the negative control. The final volume in each well was $200 \mu \mathrm{L}$. Plates were incubated at $37^{\circ} \mathrm{C}$ for $24 \mathrm{~h}$. The MIC was defined as the lowest concentration of the extract to inhibit the growth of microorganisms. The MBC was interpreted as the highest dilution (lowest concentration) of the sample which showed clear fluid with no development of turbidity and without visible growth. T. gallica extracts tested in this study were screened twice against each microorganism.

\subsection{LC-ESI-TOF-MS analyses}

Flower and leaf extracts were obtained by magnetic stirring of $2.5 \mathrm{~g}$ dry powder in 25 $\mathrm{mL}$ pure $80 \%$ methanol for $30 \mathrm{~min}$. Each extract was kept for $24 \mathrm{~h}$ at $4{ }^{\circ} \mathrm{C}$, filtered through a Whatman $\mathrm{n}^{\circ} 4$ filter paper, passed through $\mathrm{C}_{18}$ column to eliminate chlorophyll and nonpolar compounds, and evaporated under reduced pressure at $35^{\circ} \mathrm{C}$ using rotary vacuum evaporator. At last, $1 \mathrm{~g}$ of freeze-dried extract was dissolved in methanol. Each sample was then passed through a $0.45 \mu \mathrm{M}$ nylon filter before the injection into the LC-ESI-TOF-MS system. The separation of selected phenolic compounds was carried out using an HPLC system (Agilent 1200, Agilent technologies, Germany) equipped with a reversed phase $\mathrm{C}_{18}$ analytical column of $2.5 \times 50 \mathrm{~mm}$ and $1.8 \mu \mathrm{M}$ particle size (Zorbax Eclipse XDB-C18). The mobile phase B was milli-Q water consisted of $0.1 \%$ formic acid and mobile phase A was acetonitrile. This HPLC system was connected to a time-of-flight mass spectrometer, Agilent MSD TOF (Agilent technologies, Germany), equipped with an electrospray interface operating in positive and negative modes. In this study, some parameters were used in order to increase the possibilities of separation, detection, and characterization of phenolic compounds that are responsible for the biological activities. During the chromatographic steps, the column temperature was maintained at $23^{\circ} \mathrm{C}$, the flow rate of the mobile phase was $0.4 \mathrm{~mL} / \mathrm{min}$, and 
the injected sample volume was $2 \mu \mathrm{L}$. The optimised gradient elution was: $0-10$ min, $10-30 \%$ A; 10-25 min, 30-50\% A; 25-50 min, 50-80\% A; 50-60 min, 80-10\% A; 60-65 min, return to initial conditions. The MS conditions were illustrated using the following operation parameters: the capillary voltage was $3500 \mathrm{~V}$, the nebuliser pressure: 30 psig, drying gas: 8 1/min, gas temperature: $325^{\circ} \mathrm{C}$, fragmentor voltage fragment: $175 \mathrm{~V}$, skimmer voltage: $65 \mathrm{~V}$ and octopole RF: $750 \mathrm{~V}$. LC/MS accurate mass spectra were recorded across the range 100$3000 \mathrm{~m} / \mathrm{z}$. During this work, the electrospray ionization was operated in positive mode. The data recorded was processed with MassHunter software (Waldbronn, Germany) with accurate mass application specific additions from Agilent MSD TOF software. UV absorption spectra were recorded online during the HPLC analysis. The DAD detector was set to a scanning range of 200-400 $\mathrm{nm}$. The phenolic compounds were identified mainly by their UV-spectra, ESI-MS spectra and by comparing with published data.

\subsection{Statistical analysis}

For all plant parameters, all samples were analyzed in three replications. Data are shown as mean \pm sd. A one-way analysis of variance (ANOVA) using the post hoc analyse with Duncan's test was carried out to test any significant differences at $p<0.05$.

\section{Results and discussion}

\subsection{Determination of antimicrobial activities}

In the present work, results illustrated in Table 1 compared the antimicrobial activity of T. gallica between leaf (Fig. 4A1) and flower (Fig. 4A2) organs and between concentrations $(50,100$ and $300 \mathrm{mg} / \mathrm{mL})$. In Tunisian traditional medicine, several plants with high antioxidant capacities are used against a wide range of bacterial and fungal strains. Among these plants, there are Frankenia (Megdiche Ksouri et al., 2011), Suaeda (EL-Hagrasi et al., 2005), Limoniastrum (Trabelsi et al., 2010), and Mesembryanthemum species (Falleh et al., 2013). In the present study, and independently of extracts, diameters of the inhibition zone (including the diameter of the disc) vary significantly from 6 to $25 \mathrm{~mm}$ using bacteria and from 7.33 to $14.67 \mathrm{~mm}$ using Candida spp. strains tested. For both activities, the efficacy of all extracts increased with the concentration and reached a maximum at $300 \mathrm{mg} / \mathrm{mL}$. Moreover, and regardless strains and concentrations, flowers are the potent organs with the 
most important inhibition haloes (up to $25 \mathrm{~mm}$ ) than those of leaf extracts (maxima 14.33 $\mathrm{mm})$. The same tendency was shown with the fungal strains with a diameter of inhibition zone ranging from 12 (against $C$. glabrata) to $14.67 \mathrm{~mm}$ (against C. albicans). T. gallica is a valuable source of active antioxidant compounds (Ksouri et al., 2009). In fact, authors showed that leaves and flowers of $T$. gallica collected in Takelsa locality present high antimicrobial activities. In the present study, flowers showed high antibacterial (up to $15 \mathrm{~mm}$ ) and antifungal (up to $8.66 \mathrm{~mm}$ ) activities. In addition, the high inhibitory effect of flower extracts against these pathogenics may be due to the richness of these organs in antioxidant compounds in particular phenolic acids and flavonoids (Ksouri et al., 2009). In this context, a research focused on some Argentinean herbs infusions likes Lippia integrifolia, Mentha piperita and Ilex paraguaiensis showed an antibacterial activity in association with their antioxidant capacities (Rodríguez Vaquero et al., 2010).

Independently of concentrations, $M$. luteus strain was the most sensitive to the effect of leaves and flowers with a diameter of inhibition zone ranging from $14.33 \mathrm{~mm}$ (leaf extract) to $25 \mathrm{~mm}$ (flower extract). Likewise, Table 1 showed that the antimicrobial activity of methanolic extracts differs depending on the strains. Thus, P. aeruginosa, E. coli, B. subtilis, and $E$. faecalis were even more resistant to $300 \mathrm{mg} / \mathrm{mL}$ of extract with an inhibition equal to 6 $\mathrm{mm}$ diameter. Furthermore, even at high concentration of extracts, Gram-negative strains were more resistant than Gram-positive. This can be explained by the existence of the single outer peptidoglycan layer which is not an effective permeability barrier (Tadeg et al., 2005). Moreover, the inhibition of growth could be due to the permeability and the destruction of the microbial membrane, inhibiting synthesis of nucleic acids and bacteria inhibiting energy metabolism (Cushnie and Lamb, 2011). Concerning yeast treated with leaf extracts, results did not reveal any significant sensitivity except for treatment using $50 \mathrm{mg} / \mathrm{mL}$ of extract. However, a difference was observed with fungi treated with floral extracts (Table 1). In fact, C. albicans and C. glabrata are more sensitive to flower extracts than C. krusei and $C$. parapsilosis. Table 1 showed also that the antibacterial effect of both organs was more important than the antifungal one. These data suggest that the yeast strains are more resistant to bacteria. In this context, and in agreement with our results, Wilson et al. (2005) have shown that Candida albicans was the most resistant $(\mathrm{zi}=9 \mathrm{~mm})$ than Micrococcus luteus $(\mathrm{zi}=14 \mathrm{~mm})$ to Curcuma malabarica extract.

The minimal inhibition concentrations (MICs) and the minimal bactericidal concentrations (MBCs) values of $T$. gallica organ extracts tested against all strains were summarized in Table 2 and Fig. 4B. Independently of strains, results indicate that flowers 
were the most effective organs. Regardless of the extracts, the values of MICs are equal to $0,146 \mathrm{mg} / \mathrm{mL}$ against all strains except $C$. albicans $(0.3 \mathrm{mg} / \mathrm{mL})$. Results did not show difference between Gram-positive and Gram-negative strains. Regarding MBCs, results showed concentrations superior to $37 \mathrm{mg} / \mathrm{mL}$ using leaf extracts and $18 \mathrm{mg} / \mathrm{mL}$ using flower ones. This difference between the two organs as well as the difference in bacterial and fungal sensitivities could be attributable to the structure of compounds (Cushnie and Lamb, 2011; Tian et al., 2009). In agreement with the work of Marmonier (1990), an extract is bacteriostatic when $\mathrm{MBC} / \mathrm{MIC} \geq 4$ and bactericidal if $\mathrm{MBC} / \mathrm{MIC} \leq 4$. Based on this report, it can be advanced that both extracts of $T$. gallica have a bacteriostatic effect on all pathogens used in this study. This activity is certainly due to the natural antimicrobial agents produced in T. gallica organs. In fact, the high activity of this plant is explained by a previous study of Ksouri et al. (2009) who determined using RP-HPLC analysis that syringic acid, isoquercitin as well as catechin were the major phenolics in leaves and flowers of T. gallica.

\subsection{Identification of major phenolic compounds by LC-ESI-TOF-MS}

Table 3 showed the retention time (R.T), $\mathrm{m} / \mathrm{z}$, the maximum absorbance, and formulas of various phenolic compounds identified from the two organs of T. gallica. Moreover, the total ion chromatograms (TIC) of T. gallica flower and leaf extracts obtained by LC-ESITOF-MS were respectively shown in Fig. 1A and B. In this study, UV-spectrum at $280 \mathrm{~nm}$ in positive mode of ESI mass detection was employed. Five compounds were identified in flower extracts (Fig. 1A) and six in leaf ones (Fig. 1B). However, some metabolites are still unidentified in flower extracts (peak 5) and leaf extracts (peaks 1, 6, 7, 8, and 10).

The analysis of $T$. gallica extracts by LC-ESI-TOF-MS allowed us the identification of several phenolic compounds that are already recognized by their abundance in the Tamaricaceae family. In agreement with the literature, the phenolic compounds identified in the flowers (Fig. 2) are: coumarin $(\mathrm{m} / \mathrm{z}=147.0433)$ (Djurdjević et al., 2006; Sultanova et al., 2001), quercetin 3-O-glucuronide $(\mathrm{m} / \mathrm{z}=479.0845)$ (Ksouri et al., 2009), quercetin $(\mathrm{m} / \mathrm{z}$ $=303.0509)$, kaempferol $(\mathrm{m} / \mathrm{z}=287.0550)$, and one heterosid: the rhamnocitrin $(\mathrm{m} / \mathrm{z}$ $=301.0695$ ) (Souliman et al., 1991). Quercetin and kaempferol, already identified in T. gallica (Drabu et al., 2012), are among the most abundant compounds in this organ. Regarding leaves (Fig. 3), the analysis showed the existence of six flavonoid compounds as: quercetin $(\mathrm{m} / \mathrm{z}$ $=303.0137)$ (Ksouri et al., 2009), quercetin 3-O-glucuronide $(\mathrm{m} / \mathrm{z}=479.0829)$ which was identified in Reaumuria soongarica (Tamaricaceae) (Iwashina et al., 2012), kaempferol 3-O- 
$\beta$-D-glucuronide $(\mathrm{m} / \mathrm{z}=463.0877)$ which was identified and isolated in Tamarix nilotica (Nawwar et al., 1984), flavone $(\mathrm{m} / \mathrm{z}=223.1902)$ (Ksouri et al., 2009), (-)-epicatechin $(\mathrm{m} / \mathrm{z}$ =291.1136) (Ksouri et al., 2009), and a sterol as the resveratrol 3-O-glucoside $(\mathrm{m} / \mathrm{z}$ =391.2835) (Drabu et al., 2012). Results showed that there are common compounds in both extracts such as quercetin and quercetin 3-O-glucuronide. In addition, analysis by LC-ESITOF-MS revealed that some metabolites are identified in heterogeneous molecular forms with a substituent such as glucuronide or glucoside.

This study revealed that leaves of $T$. gallica as well as the flowers present an important antimicrobial activity. This biological effect seems to be explained by the nature of the bioactive compounds found in these extracts by LC-ESI-TOF-MS. Halophytes are known for their bioactive molecules associated with high biological activities. For example, different fractions of Limoniastrum guyonianum which were known for their high antioxidant capacity, has a significant inhibitory effect of bacterial growth against Staphylococcus aureus, Enterococcus faecalis, Escherichia coli, Pseudomonas aeruginosa, and Salmonella typhi with inhibition zone diameters superior to $13 \mathrm{~mm}$. This antimicrobial activity is important and due to the presence of powerful antioxidants such as catechin and phenolic acids (Trabelsi et al., 2013). Many research focused on antibacterial and antifungal activities of these molecules as natural antioxidant compounds. For example, the antibacterial activity of rhamnocitrin and quercetin, identified in Combretum erythrophyllum (Combretaceae), present an important activity against microorganism like M. luteus (Martini et al., 2004). Recently, Hirai et al. (2010) showed that quercetin has anti-Staphylococcus aureus with aggregation of cells. In the same way, research on the effect of phenolic compounds from honey showed that this extract is rich in flavonoids such as luteolin compounds, quercetin, 8-methoxykaempferol, apigenin, fisetin, kaempferol, isorhamnetin, acacetin, tamarixetin, chrysin, and galangin and strongly inhibit growth of $C$. albicans (Candiracci et al., 2012). The sensibility of this strain is due to the reduction of hyphal formation from the value of $67 \%$ in the untreated samples, to value of $32 \%(p<0.05), 24 \%(p<0.05)$, and $15 \%(p<0.001)$ corresponding to concentrations of flavonoids of 48,96 , and $192 \mu \mathrm{g} / \mathrm{mL}$, respectively. On the other hand, the sensitivity of some fungi to certain bioactive molecules may be due to an effect on the cell signalling. In the case of C. albicans, sesamol (3,4-methylenedioxyphenol), a phenolic compound obtained from sesame seed oil of Sesamum sp., revealed that the anti-candidal activity was mediated by the disruption of calcineurin signalling pathway (Ansari et al., 2014). During stress conditions, this serine-threonine phosphatase is essential to the survival and for the virulence of $C$. albicans (Blankenship et al., 2003). Moreover, the activity of phenolics can be predicted by 
their molecular properties and structural characteristics (Cushnie and Lamb, 2011). In our study, flowers are rich on coumarin. In fact, previous researches showed that the daphnetin, an example of coumarin provided from stems of Daphne gnidium L., exhibited antibacterial activity against B. lentus and E. coli (Cottiglia et al., 2001).

In conclusion, these results have established that leaves and flowers of $T$. gallica exhibited high in vitro antibacterial and antifungal activities. Moreover, results showed that this edible specie is rich on bioactive molecules. These data suggest that $T$. gallica, as a medicinal halophyte, could be a promising source of natural products in the field of functional foods and nutraceutical industries.

\section{Acknowledgements}

This study was supported by the Tunisian Ministry of Higher Education, Scientific Research, Information and Communication Technologies (LR10CBBC02) and was performed in the framework of the JICA-JST Science and Technology Research Partnership for Sustainable Development (SATREPS) Project: "Valorization of Bio-resources in Semi-Arid and Arid Land for Regional Development”.

\section{Contributions}

Dr. Mondher Boulaaba: Establishment of all the manipulations from the collection of samples, the extractions, the phenolics dosage, and until the antioxidant and the antimicrobial activities estimation, besides the redaction of the manuscript. Dr. Mejdi Snoussi: provided us all the microorganisms that we used in this work and with Dr. Mariem Saada contributed by scientific guidance during manipulations of the antimicrobial activities. Dr. Khaoula Mkadmini: Contributed by the injection of the extracts in the LC-ESI-TOF-MS and the identification of the phenolic composition. Pr. Abderrazak Smaoui: The botanist who authenticated specimens of the plant in their native ecosystems and established their taxonomic identification. Pr. Chedly Abdelly: Scientific and administrative director of the laboratory where conducted the research work and he contributed by the final revision of the manuscript. Pr. Riadh Ksouri: Scientific direction and supervisor of the whole research work besides correction of the manuscript. 


\section{References}

Ansari, M.A., Fatima, Z., Hameed, S. 2014. Sesamol: A Natural Phenolic Compound with Promising Anticandidal Potential. J. Pathog. 2014, 895193. doi:10.1155/2014/895193 Blankenship, J.R., Wormley, F.L., Boyce, M.K., Schell, W.A., Filler, S.G., Perfect, J.R., Heitman, J. 2003. Calcineurin is essential for Candida albicans survival in serum and virulence. Eukaryot Cell. 2, 422-30.

Boulaaba, M., Mkadmini, K., Tsolmon, S., Han, J., Smaoui, A., Kawada, K., Ksouri, R., Isoda, H., Abdelly, C., 2013a. In vitro antiproliferative effect of Arthrocnemum indicum extracts on Caco-2 cancer cells through cell cycle control and related phenol LC-TOF-MS identification. Evid Based Complement Alternat Med. doi.org/10.1155/2013/529375

Boulaaba, M., Tsolmon, S., Ksouri, R., Han, J., Kawada, K., Smaoui, A., Abdelly, C., Isoda, H., 2013b. Anticancer effect of Tamarix gallica extracts on human colon cancer cells involves Erk1/2 and p38 action on $\mathrm{G}_{2} / \mathrm{M}$ cell cycle arrest. Cytotechnology. 65, 927936.

Boulekbache-Makhlouf, L., Slimani, S., Madani, K., 2013. Total phenolic content, antioxidant and antibacterial activities of fruits of Eucalyptus globulus cultivated in Algeria. Ind. Crop. Prod. 41, 85-89.

Candiracci, M., Citterio, B., Piatti, E., 2012. Antifungal activity of the honey flavonoid extract against Candida albicans. Food. Chem. 131, 493-499.

Cottiglia, F., Loy, G., Garau, D., Floris, C., Casu, M., Pompei, R., Bonsignore, L., 2001. Antimicrobial evaluation of coumarins and flavonoids from the stems of Daphne gnidium L. Phytomedicine. 8, 302-305.

Cushnie, T.P.T., Lamb, A.J., 2011. Recent advances in understanding the antibacterial properties of flavonoids. Int. J. Antimicrob. Agents. 38, 99-107.

Cushnie, T.P.T., Lamb, A.J., 2005. Antimicrobial activity of flavonoids. Int. J. Antimicrob. Ag. 26, 343-356.

De Lima Procópio, R.E., da Silva, I.R., Martins, M.K., de Azevedo, J.L., de Araújo, J.M., 2012. Antibiotics produced by Streptomyces. Braz. J. Infect. Dis. 16, 466-471.

De Souza, S.M., Monache, F.D., Smânia, A.Jr., 2005. Antibacterial activity of coumarins. Z. Naturforsch. C. 60, 693-700.

Djurdjević, L., Mitrović, M., Avlović, P., Gajić, G., Ostić, O., 2006. Phenolic acids as bioindicators of fly ash deposit revegetation. Arch. Environ. Con. Tox. 50, 488-495. 
Drabu, S., Chaturvedi, S., Sharma, M., 2012. Tamarix gallica-An overview. Asian. J. Pharm. Clin. Res. 5, 17-19.

Eldeen, I.M.S., Seow, E.M., Abdullah, R., Sulaiman, S.F., 2011. In vitro antibacterial, antioxidant, total phenolic contents and anti-HIV-1 reverse transcriptase activities of extracts of seven Phyllanthus sp. S. Afr. J. Bot. 77, 75-79.

El-Hagrasi, A.M.A., El-Desouky, S.K., El Ansari, M.A., Rabie, A.M., 2005. Investigation of lipid constituents of pods of Caesalpinia pulcherrima L., aerial parts of Suaeda pruinosa Forssk. and antimicrobial activity of their methanolic extracts. Bull. NRC Egypt 30, 133-140.

Falleh, H., Trabelsi, N., Bonenfant-Magné, M., Le Flochc, G., Abdelly, C., Magné, C., Ksouri., R., 2013. Polyphenol content and biological activities of Mesembryanthemum edule organs after fractionation. Ind. Crop. Prod. 42, 145-152.

Gulluce, M., Sahin, F., Sokmen, M., Ozer, H., Daferera, D., Sokmen, A., Polissiou, M., Adiguzel, A., Ozkan, H., 2007. Antimicrobial and antioxidant properties of the essential oils and methanol extract from Mentha longifolia L. ssp. longifolia. Food. Chem. 103, 1449-1456.

Hajlaoui, H., Snoussi, M., Ben Jannet, H., Mighri, Z., Bakhrouf, A., 2008. Comparison of chemical composition and antimicrobial activities of Mentha longifolia L. ssp. longifolia essential oil from two Tunisian localities (Gabes and Sidi Bouzid). Ann. Microbiol. 58, 513-520.

Hirai, I., Okuno, M., Katsuma, R., Aria, N., Tachibana, M., Yamamoto, Y., 2010. Characterisation of anti-Staphylococcus aureus activity of quercetin. Int. J. Food. Sci. Tech. $45,1250-1254$.

Iwashina, T., Smirnov, S.V., Damdinsuren, O., Kondo, K., 2012. Flavonoids from Reaumuria soongarica (Tamaricaceae) in Mongolia. Bull. Natl. Mus. Nat. Sci., Ser. B, 38, 189195.

Khan, R., Islam, B., Akram, M., Shakil, S., Ahmad, A.A., Ali, S.M., Siddiqui, M., Khan, A.U., 2009. Antimicrobial Activity of Five Herbal Extracts Against Multi Drug Resistant (MDR) Strains of Bacteria and Fungus of Clinical Origin. Molecules. 14, 586-597.

Ksouri, R., Falleh, H., Megdiche, W., Trabelsi, N., Mhamdi, B., Chaieb, K., Bakrouf, A., Magné, C., Abdelly, C., 2009. Antioxidant and antimicrobial activities of the edible medicinal halophyte Tamarix gallica L. and related polyphenolic constituents. Food. Chem. Toxicol. 47, 2083-2091. 
Lisiewska, Z., Kmiecik, W., Korus, A., 2006. Content of vitamin C, carotenoids, chlorophylls and polyphenols in green parts of dill (Anethum graveolens L.) depending on plant height. J. Food. Compost. Anal. 19, 134-140.

Marmonier, A.A., 1990. Introduction aux techniques d'étude des antibiotiques. In Bactériologie Médicale, Techniques Usuelles, Doin, Paris, 227-236

Martini, N.D., Katerere, D.R.P., Eloff, J.N., 2004. Biological activity of five antibacterial flavonoids from Combretum erythrophyllum (Combretaceae). J. Ethnopharmacol. 93, 207-212.

Megdiche Ksouri, W., Chaouachi, F., M'Rabet, R., Medini, F., Yosr, Z., Trabelsi, N., Ksouri, R., Noumi, E., Abdelly, C., 2011. Antioxidant and antimicrobial properties of Frankenia thymifolia Desf. fractions and their related biomolecules identification by gas chromatography/mass spectrometry (GC/MS) and high performance liquid chromatography (HPLC). J. Med. Plant. Res 5, 5754-5765.

Moore, J., Liu, J.G., Zhou, K., Liangli, Y., 2006. Effects of genotype and environment on the antioxidant properties of hard winter wheat bran. J. Agric. Food. Chem 54, 5313-5322.

Mulaudzi, R.B., Ndhlala, A.R., Kulkarni, M.G., Finnie, J.F., Van Staden, J., 2011. Antimicrobial properties and phenolic contents of medicinal plants used by the Venda people for conditions related to venereal diseases. J. Ethnopharmacol. 135, 330-337.

Naczk, M., Shahidi, F., 2006. Phenolics in cereals, fruits and vegetables: occurrence, extraction and analysis. J. Pharm. Biomed. Anal. 41, 1523-1542.

Nawwar, M.A.M., Souleman, A.M.A., Buddrus, J., Linscheid, M., 1984. Flavonoids of the flowers of Tamarix nilotica. Phytochemistry 23, 2347-2349.

Oueslati, S., Ksouri, R., Falleh, H., Pichette, A., Abdelly, C., Legault, J., 2012. Phenolic content, antioxidant, anti-inflammatory and anticancer activities of the edible halophyte Suaeda fruticosa Forssk. Food. Chem. 132, 943-947.

Rodríguez Vaquero, M.J., Tomassini Serravalle, L.R., Manca de Nadra, M.C., Strasser de Saad, A.M., 2010. Antioxidant capacity and antibacterial activity of phenolic compounds from argentinean herbs infusions. Food. Control. 21, 779-785.

Rodriguez Vaquero, M.J., Alberto, M.R., Manca de Nadra, M.C., 2007. Antibacterial effect of phenolic compounds from different wines. Food Control. 18, 93-101.

Saïdana, D., Mahjoub, M.A., Boussaada, O., Chria, J., Chéraif, I., Daami, M., Mighri, Z., Helal, A.N., 2008. Chemical composition and antimicrobial activity of volatile compounds of Tamarix boveana (Tamaricaceae). Microbiol. Res. 163, 445-455. 
Sehrawat, A., Sultana, S., 2006. Evaluation of possible mechanisms of protective role of Tamarix gallica against DEN initiated and 2-AAF promoted hepatocarcinogenesis in male Wistar rats. Life. Sci. 79, 1456-1465.

Sharma, S.K., Parmar, V.S., 1998. Novel constitutes of Tamarix species. J. Sci. Ind. Res. 57, 873-890.

Souliman, A.M.A., Barakat, H.H., El-Mousallamy, A.M.D., Marzouk, M.S.A., Nawwar, M.A.M., 1991. Phenolics from the bark of Tamarix gallica. Phytochemistry. 30, 37633766.

Stoclet, J.C., Chataigneau, T., Ndiaye, M., Oak, M.H., El Bedoui, J., Chataigneau, M., SchiniKerth, V.B., 2004. Vascular protection by dietary polyphénols. Eur. J. Pharmacol. 500, 299-313.

Sultanova, N., Makhmoor, T., Abilov, Z.A., Parween, Z., Omurkamzinova, V.B., ur-Rahman A., Choudhary, M.I., 2001. Antioxidant and antimicrobial activities of Tamarix ramosissima. J. Ethnopharmacol. 77, 201-205.

Sultanova, N., Makhmoor, T., Yasin, A., Abilov, Z.A., Omurkamzinova, V.B., Choudhary, M.I., 2004. A new antioxidant and prolyl endopeptidase-inhibiting triterpenoid from Tamarix hispida. Planta. Med. 70, 65-67.

Tadeg, H., Mohammed, E., Asres, K., Gebre-Mariam, T., 2005. Antimicrobial activities of some selected traditional Ethiopian medicinal plants used in the treatment of skin disorders. J. Ethnopharmacol. 100, 168-175.

Tian, F., Li, B., Ji, B., Yang, J., Zhang, G., Chen, Y., Luo, Y., 2009. Antioxidant and antimicrobial activities of consecutive extracts from Galla chinensis: The polarity affects the bioactivities. Food. Chem. 113, 173-179.

Trabelsi, N., Megdiche, W., Ksouri, R., Falleh, H., Oueslati, S., Bourgou, S., Hajlaoui, H., Abdelly, C., 2010. Solvent effects on phenolic contents and biological activities of the halophyte Limoniastrum monopetalum leaves. LWT. Food. Sci. Technol. 43, 632-639.

Trabelsi, N., Oueslati, S., Henry-Vitrac, C., Waffo-Téguo, P., Medini, F., Mérillon, J.M., Abdelly, C., Ksouri, R., 2013. Phenolic contents and biological activities of Limoniastrum guyonianum fractions obtained by Centrifugal Partition Chromatography. Ind. Crop. Prod. 49, 740-746.

Wilson, B., Abraham, G., Manju, V.S., Mathew, M., Vimala, B., Sundaresan, S., Nambisan, B., 2005. Antimicrobial activity of Curcuma zedoaria and Curcuma malabarica tubers. J. Ethnopharmacol. 99, 147-151. 
511 Fig. 1. (Aa) Total ion chromatogram (TIC) of T. gallica flower extracts obtained by LC-ESITOF-MS, (Ab) HPLC/UV chromatogram $(280 \pm 4 \mathrm{~nm})$ for each protonated molecule (Positive mode). Peaks designation: (1) Coumarin, (2) Quercetin 3-O-glucuronide, (3) Quercetin, (4) Kaempferol, (5) Not identified, (6) Rhamnocitrin, (Ba) Total ion chromatogram (TIC) of $T$. gallica leaf extracts obtained by LC-ESI-TOF-MS, and (Bb) HPLC/UV chromatogram (280 $\pm 4 \mathrm{~nm})$ for each protonated molecule (Positive mode). Peaks designation: (1) Not identified, (2) Querctine,

(3) Quercetin 3-O-glucuronide, (4) Kaempferol 3-O- $\beta$-Dglucuronide, (5) Flavone, (6) Not identified, (7) Not identified, (8) Not identified, (9) (-)Epicatechin, (10) Not identified, (11) Resveratrol 3-O-glucoside.

Fig. 2. Extract ion chromatogram/mass spectra of each protonated molecule (positive mode) provided from flower extracts of T. gallica: Peak 1: Coumarin, Peak 2: Quercetin 3-Oglucuronide, Peak 3: Quercetin, Peak 4: Kaempferol, and Peak 5: Rhamnocitrin.

Fig. 3. Extract ion chromatogram/mass spectra of each protonated molecule (positive mode) provided from leaf extracts of T. gallica: Peak 2: Quercetin, Peak 3: Quercetin 3-Oglucuronide, Peak 4: Kaempferol 3-O- $\beta$-D-glucuronide, Peak 5: Flavone, Peak 9: (-)Epicatechin, Peak 11: Resveratrol 3-O-glucoside.

Fig. 4. Antimicrobial activities of T. gallica extracts against bacteria and fungi. (A) Agar disk diffusion assay of leaf (A1) and flower (A2) extracts. Concentrations: C1, C2 and C3: 50, 100 and $300 \mathrm{mg} / \mathrm{mL}$ respectively. Microorganisms: M1: Pseudomonas aeruginosa, M2: Salmonella arizonae, M3: Escherichia coli, M4: Klebsiella sp., M5: Staphylococcus aureus, M6: Micrococcus luteus, M7: Enterococcus faecalis, M8: Bacillus subtilis, M9: Listeria monocytogenes, M10: Staphylococcus aureus MR, M11: Bacillus thuringiensis, M12: Bacillus cereus, M13: Candida albicans, M14: Candida glabrata, M15: Candida krusei, M16: Candida parapsilosis, (B) Broth microdilution assay to determine the MIC and MBC in the presence or absence (control) of plant extracts. Plates: 1 and 2: Extracts of leaves and flowers respectively. 
Table 1. Antibacterial and antifungal activities of leaf and flower extracts of T. gallica.

\begin{tabular}{|c|c|c|c|c|c|c|c|c|}
\hline \multirow{2}{*}{ Microorganisms } & \multicolumn{3}{|c|}{ Leaves (mg/mL) } & \multicolumn{3}{|c|}{ Flowers (mg/mL) } & \multicolumn{2}{|c|}{ Antibiotics } \\
\hline & 50 & 100 & 300 & 50 & 100 & 300 & Gent & $\mathbf{C}$ \\
\hline \multicolumn{9}{|l|}{ Bacteria } \\
\hline P. aeruginosa ATCC 27853 & $6.00 \pm 0.00 l$ & $6.00 \pm 0.00 l$ & $6.00 \pm 0.001$ & $9.67 \pm 0.58 i j$ & $11.67 \pm 0.58 g$ & $13.67 \pm 0.58 d$ & 46 & 12 \\
\hline S. arizonae DMB 560 & $6.00 \pm 0.00 l$ & $7.00 \pm 0.00 \mathrm{kl}$ & $9.00 \pm 0.00 \mathrm{hi}$ & $8.00 \pm 0.00 m$ & $9.00 \pm 0.00 \mathrm{kl}$ & $11.00 \pm 0.00 \mathrm{~h}$ & 6 & 36 \\
\hline E. coli ATCC 35218 & $6.00 \pm 0.00 l$ & $6.00 \pm 0.00 l$ & $6.00 \pm 0.00 l$ & $6.00 \pm 0.00 n$ & $6.00 \pm 0.00 n$ & $10.00 \pm 0.00 i$ & 42 & 34 \\
\hline Klebsiella sp. CIP Tunis & $6.00 \pm 0.00 l$ & $6.00 \pm 0.00 l$ & $9.67 \pm 0.58 f g$ & $9.00 \pm 0.00 \mathrm{kl}$ & $9.67 \pm 0.58 i j$ & $12.33 \pm 0.58 \mathrm{f}$ & 22 & 18 \\
\hline M. luteus NCIMB 8166 & $10.67 \pm 0.58 e f$ & $12.33 \pm 0.58 b$ & $14.33 \pm 0.58 a$ & $15.33 \pm 0.58 c$ & $17.67 \pm 0.58 b$ & $25.00 \pm 0.00 a$ & 36 & 16 \\
\hline E. faecalis ATCC 29212 & $6.00 \pm 0.00 l$ & $6.00 \pm 0.00 l$ & $6.00 \pm 0.00 l$ & $6.00 \pm 0.00 n$ & $6.00 \pm 0.00 \mathrm{n}$ & $7.67 \pm 0.58 m$ & 44 & 46 \\
\hline B. subtilis ATCC 6623 & $6.00 \pm 0.00 l$ & $6.00 \pm 0.00 l$ & $6.00 \pm 0.00 l$ & $6.00 \pm 0.00 n$ & $11.00 \pm 0.00 h$ & $9.00 \pm 0.00 \mathrm{kl}$ & 17 & 26 \\
\hline L. monocytogenes ATCC 19115 & $8.00 \pm 0.00 j$ & $9.00 \pm 0.00 h i$ & $11.00 \pm 0.00 \mathrm{de}$ & $9.00 \pm 0.00 \mathrm{kl}$ & $10.00 \pm 0.00 i$ & $11.00 \pm 0.00 h$ & 30 & 34 \\
\hline S. aureus MR & $7.00 \pm 0.00 \mathrm{kl}$ & $11.33 \pm 0.58 c d$ & $14.00 \pm 0.00 a$ & $6.00 \pm 0.00 n$ & $8.67 \pm 0.58 l$ & $10.67 \pm 0.58 h$ & 6 & 8 \\
\hline C. albicans ATCC 90026 & $7.33 \pm 0.58 d$ & $10.00 \pm 0.00 b$ & $12.33 \pm 0.58 a$ & $9.67 \pm 0.58 f$ & $11.67 \pm 0.58 d$ & $14.33 \pm 0.58 a b$ & 11 & - \\
\hline C. glabrata ATCC 90030 & $7.33 \pm 0.58 d$ & $9.67 \pm 0.58 b$ & $12.67 \pm 0.58 a$ & $10.00 \pm 0.00 e$ & $12.67 \pm 0.58 c$ & $14.67 \pm 0.58 a$ & 14 & - \\
\hline C. krusei ATCC 6258 & $8.00 \pm 0.00 c$ & $10.00 \pm 0.00 b$ & $12.00 \pm 0.00 a$ & $8.00 \pm 0.00 \mathrm{~g}$ & $9.00 \pm 0.00 f$ & $12.00 \pm 0.00 c d$ & 12 & - \\
\hline C. parapsilosis ATCC 22019 & $8.00 \pm 0.00 c$ & $10.00 \pm 0.00 b$ & $12.00 \pm 0.00 a$ & $9.67 \pm 0.58 e f$ & $11.67 \pm 0.58 d$ & $13.67 \pm 0.58 b$ & 10 & - \\
\hline
\end{tabular}

SD : standard de déviation ; Gent, Gentamicine ; Amph, Amphotericine B; C, Chloramphenicol. Diameter of disc used is equal to $6 \mathrm{~mm}$. no antimicrobial activity (-), zi < $1 \mathrm{~mm}$; weakly antimicrobial activity, zi $=1$ $\mathrm{mm}$; light antimicrobial activity, zi $=2-3 \mathrm{~mm}$; moderate antimicrobial activity, zi $=4-1 \mathrm{~mm}$; high antimicrobial activity, zi $=6-9 \mathrm{~mm}$; strong antimicrobial activity, zi > $9 \mathrm{~mm}$. Values with same letters are significantly different at $p=0.05$ 
Table 2. Minimal inhibition concentrations (MICs) and minimal bactericidal concentrations (MBCs) values of selected extracts of $T$. gallica against bacteria and fungi.

\begin{tabular}{|c|c|c|c|c|}
\hline \multirow[b]{2}{*}{ Microorganisms } & \multicolumn{2}{|c|}{ Leaves } & \multicolumn{2}{|c|}{ Flowers } \\
\hline & $\begin{array}{c}\text { MIC } \\
(\mathrm{mg} / \mathrm{mL})\end{array}$ & $\begin{array}{c}\mathrm{MBC} \\
(\mathrm{mg} / \mathrm{mL})\end{array}$ & $\begin{array}{c}\text { MIC } \\
(\mathrm{mg} / \mathrm{mL})\end{array}$ & $\begin{array}{c}\text { MBC } \\
(\mathrm{mg} / \mathrm{mL})\end{array}$ \\
\hline \multicolumn{5}{|l|}{ Bacteria } \\
\hline P. aeruginosa ATCC2753 & 0,146 & $>37.50$ & 0,146 & $>18.75$ \\
\hline S. arizonae DMB 560 & 0,146 & $>37.50$ & 0,146 & $>37.50$ \\
\hline E. coli ATCC 35218 & 0,146 & $>37.50$ & 0,146 & $>18.75$ \\
\hline Klebsiella sp. CIP Tunis & 0,146 & $>37.50$ & 0,146 & $>37.50$ \\
\hline S. aureus ATCC 29213 & 0,146 & $>37.50$ & 0,146 & $>18.75$ \\
\hline M. luteus NCIMB 8166 & 0,146 & $>37.50$ & 0,146 & $>18.75$ \\
\hline E. faecalis ATCC 29212 & 0,146 & 37.50 & 0,146 & 18.75 \\
\hline B. subtilis ATCC 6623 & 0,146 & $>37.50$ & 0,146 & $>18.75$ \\
\hline L. monocytogenes ATCC 19115 & 0,146 & $>18.75$ & 0,146 & $>18.75$ \\
\hline S. aureus MR & 0,146 & $>75.00$ & 0,146 & 37.50 \\
\hline B. thuringiensis DH 110 & 0,146 & $>37.50$ & 0,146 & $>18.75$ \\
\hline B. cereus ATCC 14579 & 0,146 & $>37.50$ & 0,146 & $>9.38$ \\
\hline \multicolumn{5}{|l|}{ Fungi } \\
\hline C. albicans ATCC 90026 & 0,292 & $>150.00$ & 0,146 & $>37.50$ \\
\hline C. glabrata ATCC 90030 & 0,146 & $>37.50$ & 0,146 & $>37.50$ \\
\hline C. krusei ATCC 6258 & 0,146 & $>75.00$ & 0,146 & $>37.50$ \\
\hline C. parapsilosis ATCC 22019 & 0,146 & 150.00 & 0,146 & 75.00 \\
\hline
\end{tabular}


Table 3. Bioactive secondary metabolites identified by LC-ESI-TOF-MS in flower (peaks 1-6) and leaf (peaks 1-11) extracts of $T$. gallica. R.T: Retention times

\begin{tabular}{|c|c|c|c|c|c|c|}
\hline Organs & Peaks & R.T (min) & $\begin{array}{c}m / z \\
{[\mathbf{M}+\mathbf{H}]^{+}}\end{array}$ & $\lambda_{\max }(\mathrm{nm})$ & $\begin{array}{l}\text { Molecular } \\
\text { formula }\end{array}$ & Compounds \\
\hline \multirow{6}{*}{ Flowers } & 1 & 4,309 & 147,0433 & $230,300,310$ & $\mathrm{C}_{9} \mathrm{H}_{6} \mathrm{O}_{2}$ & Coumarin \\
\hline & 2 & 7,281 & 479,0845 & 255,355 & $\mathrm{C}_{21} \mathrm{H}_{18} \mathrm{O}_{13}$ & Quercetin 3-O-glucuronide \\
\hline & 3 & 8,412 & 303,0509 & 255,350 & $\mathrm{C}_{15} \mathrm{H}_{10} \mathrm{O}_{7}$ & Quercetin \\
\hline & 4 & 9,665 & 287,0550 & 265,345 & $\mathrm{C}_{15} \mathrm{H}_{10} \mathrm{O}_{6}$ & Kaempferol \\
\hline & 5 & 13,382 & 584,2723 & $225,295,310$ & & NI \\
\hline & 6 & 13,669 & 301,0695 & 265,350 & $\mathrm{C}_{16} \mathrm{H}_{12} \mathrm{O}_{6}$ & Rhamnocitrin \\
\hline \multirow{11}{*}{ Leaves } & 1 & 5,139 & 279,0169 & $220,265,300$ & & NI \\
\hline & 2 & 6,569 & 303,0137 & 255,370 & $\mathrm{C}_{15} \mathrm{H}_{10} \mathrm{O}_{7}$ & Quercetin \\
\hline & 3 & 7,158 & 479,0829 & 255,355 & $\mathrm{C}_{21} \mathrm{H}_{18} \mathrm{O}_{13}$ & Quercetin 3-O-glucuronide \\
\hline & 4 & 8,305 & 463,0877 & 265,350 & $\mathrm{C}_{21} \mathrm{H}_{18} \mathrm{O}_{12}$ & Kaempferol 3-O- $\beta$-D-glucuronide \\
\hline & 5 & 9,476 & 223,1902 & 290,265 & $\mathrm{C}_{15} \mathrm{H}_{10} \mathrm{O}_{2}$ & Flavone \\
\hline & 6 & 10,171 & 314,1386 & 260,350 & & NI \\
\hline & 7 & 12,085 & 353,0325 & 290,340 & & $\mathrm{NI}$ \\
\hline & 8 & 13,450 & 181,1227 & 270,350 & & NI \\
\hline & 9 & 15,065 & 291,1136 & 265,350 & $\mathrm{C}_{15} \mathrm{H}_{14} \mathrm{O}_{6}$ & (-)-Epicatechin \\
\hline & 10 & 18,296 & 343,2954 & $255,270,350$ & & NI \\
\hline & 11 & 45,998 & 391,2835 & 280 & $\mathrm{C}_{20} \mathrm{H}_{22} \mathrm{O}_{8}$ & Resveratrol 3-O-glucoside \\
\hline
\end{tabular}


(A)
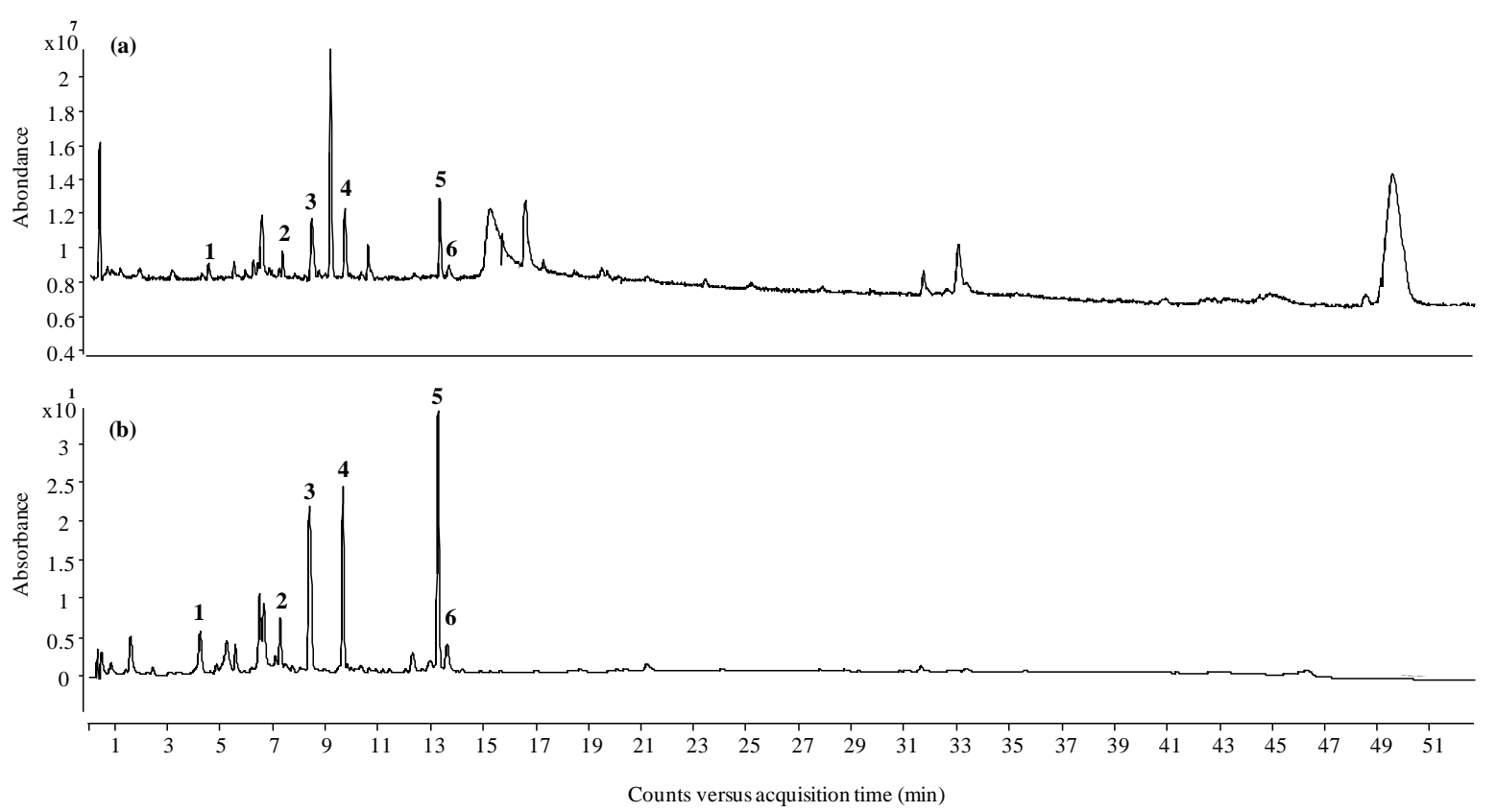

(B)
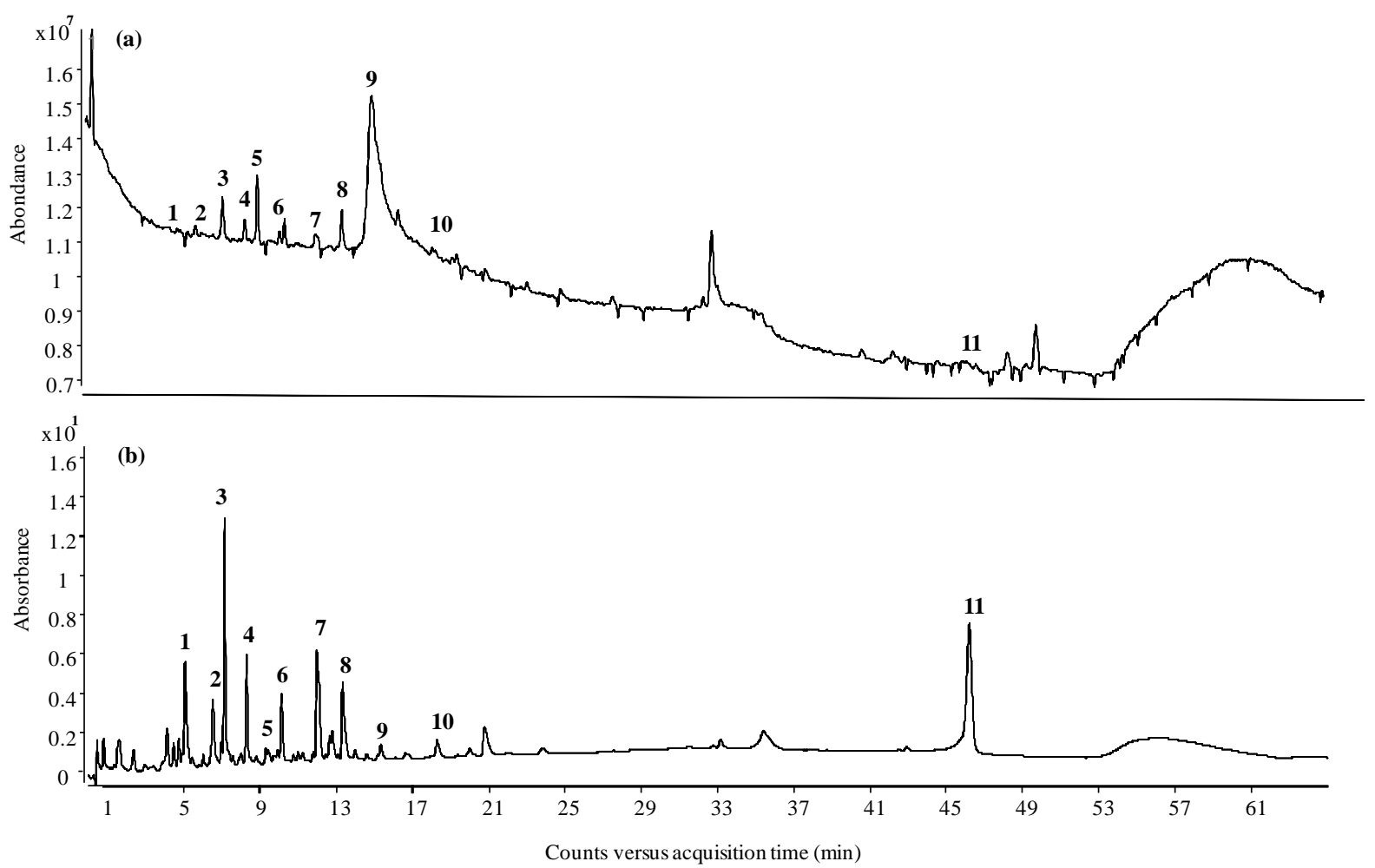

Fig. 1. 

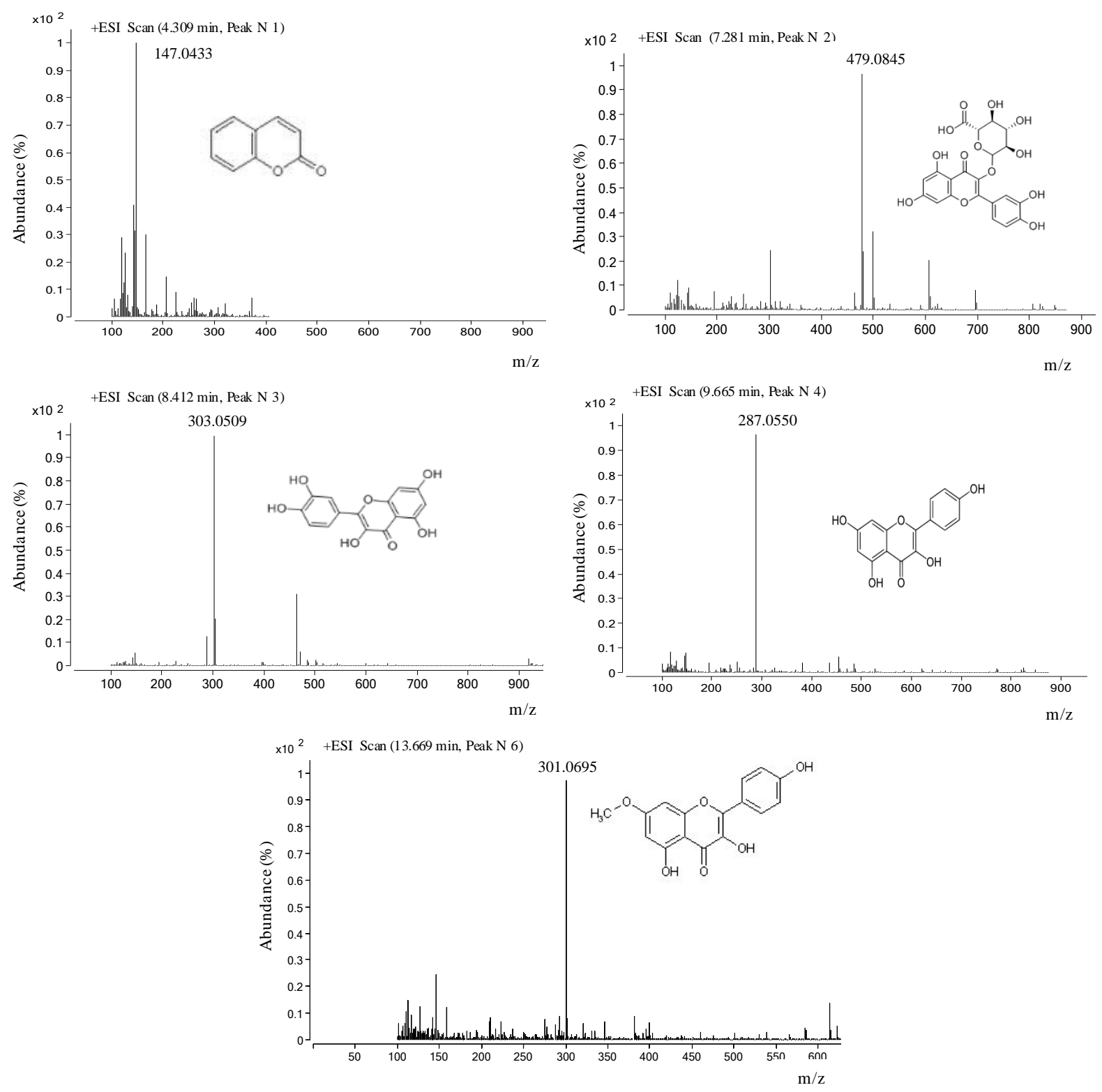

Fig. 2. 

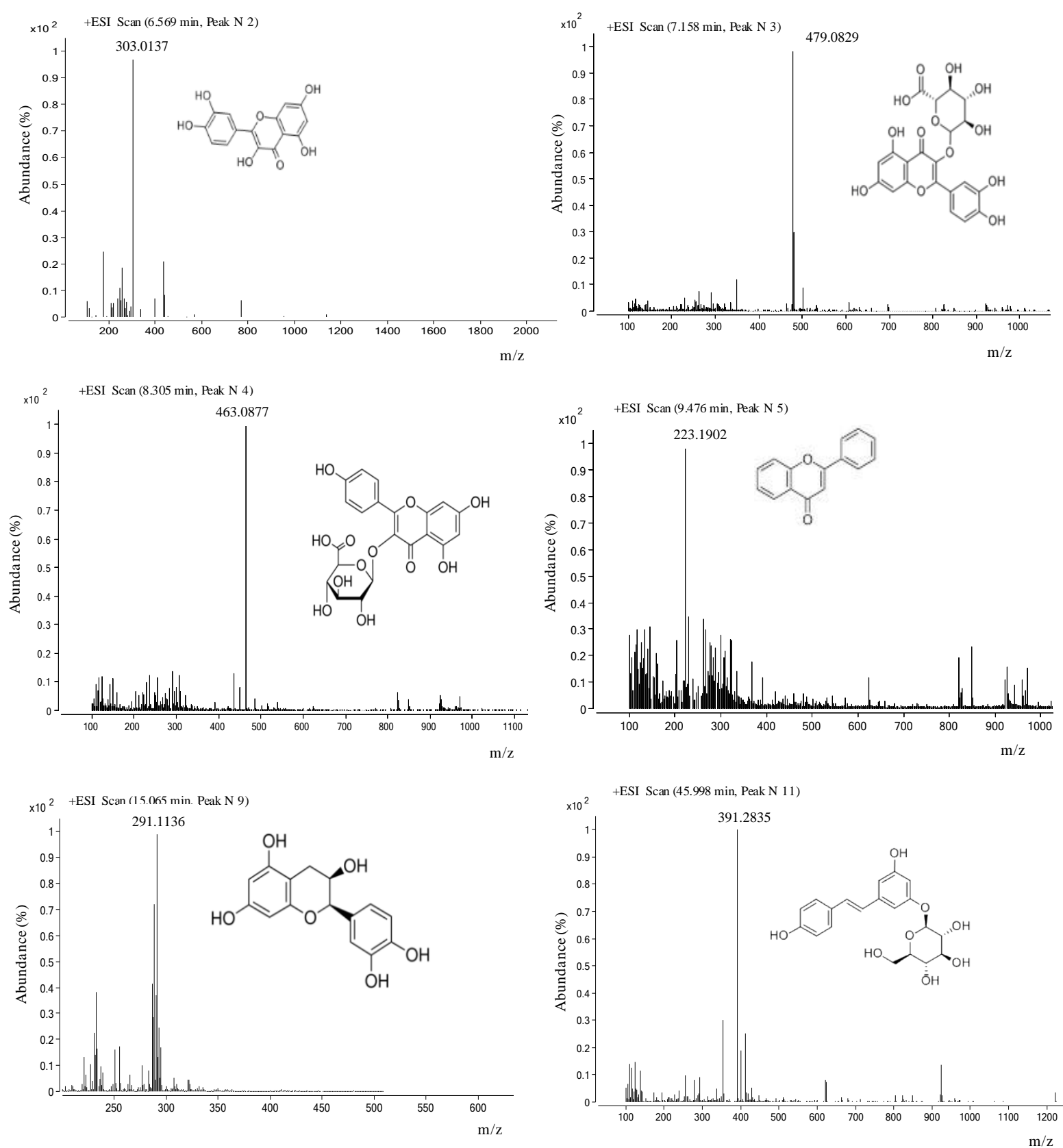

Fig. 3. 


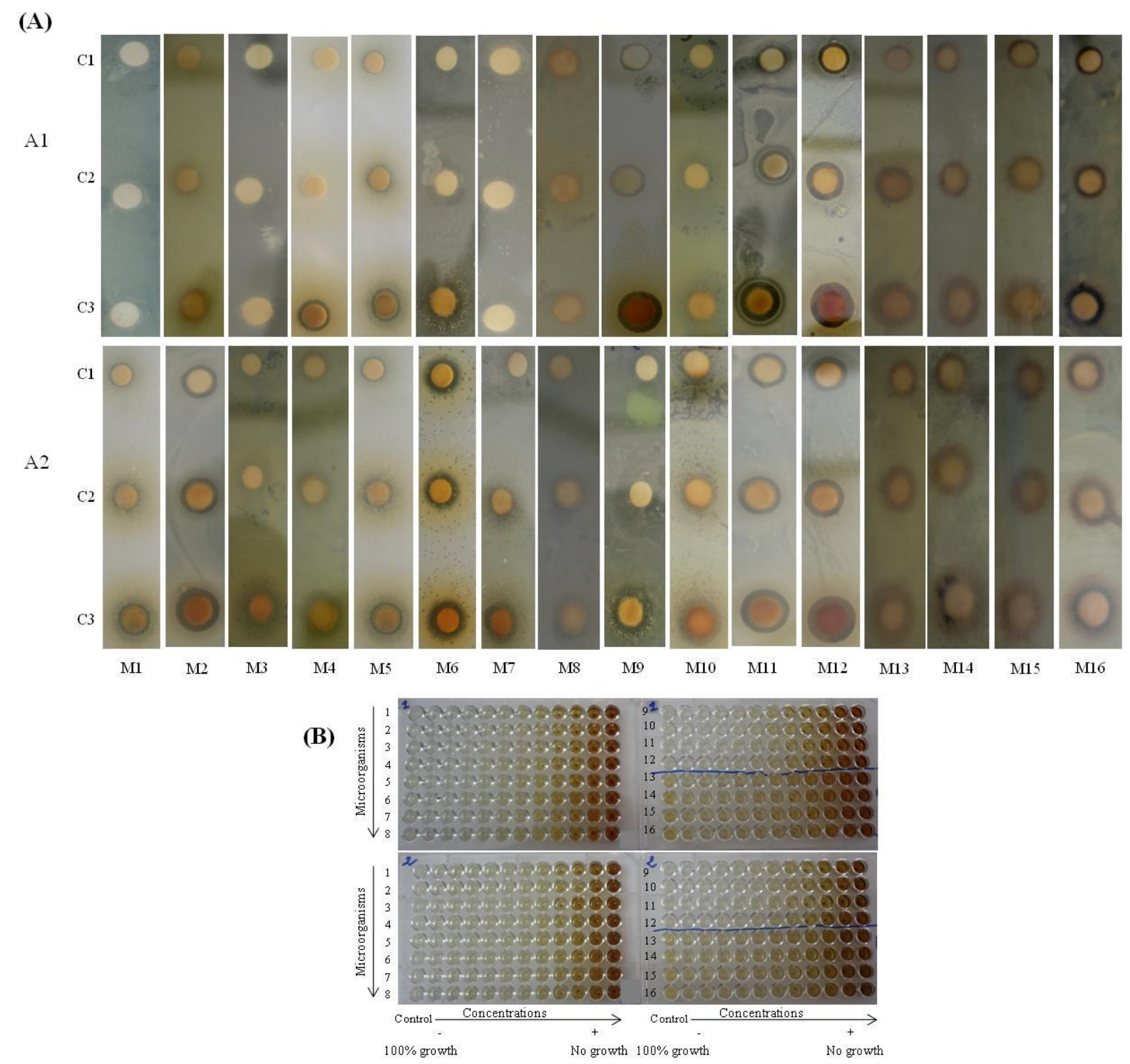

Fig. 4. 